\title{
INCIDENCIAS DE LA AGENDA PÚBLICA EN LAS ACTITUDES POLÍTICAS DEL CIUDADANO A TRAVÉS DE LA TEORÍA DE EFECTOS OLVIDADOS
}

\section{INCIDENCES OF THE PUBLIC AGENDA ON CITIZENS' POLITICAL ATTITUDES THROUGH THE THEORY OF FORGOTTEN EFFECTS}

Mauricio Ortigosa Hernández

Facultad de Economía y Negocios Universidad Anáhuac México

Huixquilucan, Estado de México-México

mauricio.ortigosa@anahuac.mx

Fecha de recepción: 30/01/2020 - Fecha de revisión: 20/04/2020 - Fecha de aprobación: 11/06/2020

DOI: https://doi.org/10.36995/j.visiondefuturo.2021.25.01.001.es

\section{RESUMEN}

El presente estudio contribuye al campo del marketing político, a través del uso de instrumentos basados en la Teoría de los Efectos Olvidados. Según esta teoría, los individuos al valuar las incidencias o conexiones entre dos conjuntos de entidades que actúan, una como causas y la otra como efectos, en ocasiones quedan ocultos elementos interpuestos surgiendo de esa manera los efectos olvidados.

Para mostrar lo anterior, se solicitó a un grupo de ciudadanos del poniente de la zona metropolitana de la Ciudad de México incluidos los municipios mexiquenses de Huixquilucan de Degollado y Naucalpan de Juárez, que determinaran las incidencias entre dos conjuntos de entidades: por un lado temas de México de una agenda pública, y por otro actitudes políticas que tiene el ciudadano. Las entrevistas se recabaron en fecha cercana a la campaña presidencial y cargos de elección popular del año 2018.

Los resultados indican que los ciudadanos no identificaron varios elementos que se interponen como efectos olvidados entre las dos entidades ya mencionadas, tales como la corrupción, la economía, la confianza en los gobernantes, entre otros elementos.

PALABRAS CLAVE: Efectos olvidados; Incertidumbre; Marketing político; Actitudes políticas; Agenda pública.

\section{ABSTRACT}

This study contributes to the field of political marketing through the use of instruments based on the Theory of Forgotten Effects. According to this theory, when individuals attribute value to the incidences or connections between two sets of entities, with one set acting as the cause and the other as effect, intervening elements sometimes remain hidden, thus resulting in forgotten effects.

\footnotetext{
"Visión de Futuro" Año 18, Volumen N$^{0} 25$ N 1, Enero - Junio 2021 - Pág 1 - 23 URL de la Revista: http://visiondefuturo.fce.unam.edu.ar/index.php/visiondefuturo/index URL del Documento: https://visiondefuturo.fce.unam.edu.ar/index.php/visiondefuturo/issue/view/19 ISSN 1668 - 8708 - Versión en Línea 
To demonstrate the above, a group of citizens from the western Mexico City Metropolitan Area including the townships of Huixquilucan de Degollado and Naucalpan de Juárez in the State of Mexico were asked to determine the incidences between two sets of entities: on the one hand, issues from Mexico's public agenda, and, on the other, the political attitudes of citizens. The interviews were collected shortly before the 2018 campaign for the presidency and other popularly elected offices began.

The results show that the citizens did not identify several elements that are interpolated as forgotten effects between the two entities mentioned above, such as corruption, the economy, and trust in government leaders, among others.

KEY WORDS: Forgotten effects; Uncertainty; Political marketing; Political attitudes; Public agenda.

\section{INTRODUCCIÓN}

El avance de la joven democracia mexicana ha sido gradual; desde la década de los años setenta, el sistema electoral ha tenido reformas que le han permitido que el tema de las elecciones ocupe espacios de interés para la opinión pública (B.M.S. García, 2011). El mismo autor, comenta que, en México, a pesar de todas las reformas electorales a nivel federal, el político en su ansia de poder se ve envuelto en los vicios del sistema y deja de estar al servicio de la causa que lo colocó en el puesto que ocupa.

García Montaño (2004) en su libro establece que la democracia política y electoral, es el formato más acabado con que cuentan las sociedades posmodernas para ponerse de acuerdo en los asuntos del poder público y gobierno. Por su parte, Morris (2011) menciona que México enfrenta un problema serio de falta de Estado de Derecho y respeto a la ley dentro de la sociedad (ejemplo: el mercado informal) y dentro del Estado mismo (ejemplo: la corrupción y la violación de los derechos humanos), lo que ha provocado en los mexicanos poca confianza en la ley, las instituciones del gobierno y los políticos. Duarte y Jaramillo (2009), mencionan que ese régimen autoritario que ha sido característico de la cultura política de los mexicanos en el siglo pasado, ha provocado en el ciudadano una apatía y falta de interés hacia los fenómenos políticos.

Tronco (2012) menciona que hay un supuesto fundamental: la confianza política es esencial para la democracia. En esta confianza se vinculan los ciudadanos con las instituciones diseñadas para representar sus intereses. Desafortunadamente, el mismo autor, menciona que en la Encuesta Nacional sobre Cultura Política y Prácticas Ciudadanas (ENCUP) elaborada en el año 2008 por la Secretaría de Gobernación, muestra para el caso

\footnotetext{
“Visión de Futuro" Año 18, Volumen No 25 N 1, Enero - Junio 2021 - Pág 1 - 23

URL de la Revista: http://visiondefuturo.fce.unam.edu.ar/index.php/visiondefuturo/index

URL del Documento: https://visiondefuturo.fce.unam.edu.ar/index.php/visiondefuturo/issue/view/19

ISSN 1668 - 8708 - Versión en Línea

E-mail: revistacientifica@fce.unam.edu.ar
} 
mexicano, que la desconfianza en la ciudadanía se explica principalmente por el deficiente desempeño que los ciudadanos atribuyen a sus representantes.

Rodríguez-Virgili, López-Escobar y Tolsá (2011), mencionan acertadamente que el desprestigio de la política en los últimos años en México, no debe ser un tema menor y debemos ser cautelosos por tres razones: en primer lugar, muchos ciudadanos afirman que no tienen el mínimo interés en la política; en segundo lugar, debemos tomar en cuenta que la política no significa lo mismo para todos y finalmente, el rechazo a los políticos no necesariamente es equivalente a un desinterés hacia la política; por el contrario la crítica puede ser un reflejo de interés hacia la misma.

El impacto de estas actitudes de confianza, interés, entre otras, hacia los fenómenos políticos, sean estas positivas o negativas, se estudian en el presente trabajo, a través de una técnica no convencional que intenta establecer relaciones de causalidad como lo haría el análisis de regresión o su particular técnica de ecuaciones estructurales. La herramienta que se propone se ubica en el marco de la teoría de efectos olvidados para estudiar relaciones de causalidad tanto directas como indirectas.

Para ilustrar dicha herramienta, se utilizan temas de una agenda pública elaborada por Corral (2016) en un estudio preelectoral 2011-2012 en México; esta agenda pública es considerada como las causas del modelo. Por otro lado, el modelo tomará como efectos, las actitudes políticas del ciudadano. Como resultado de la aplicación de la teoría de efectos olvidados, identificamos aquellas relaciones de incidencia o causalidad ocultas entre la agenda pública y las actitudes políticas.

\section{DESARROLLO}

\section{La agenda Pública}

En el ámbito de la ciencia política, el significado del término agenda, como lo mencionan Maldonado y Casar (2008), es simplemente un conjunto de temas o asuntos que se han de llevar a cabo o que son importantes de considerar para entender la realidad en la que vive un individuo o una sociedad.

En la literatura se contemplan diferentes agendas según los actores sociales que intervienen. Podemos distinguir: la agenda pública, la agenda política, la agenda gubernamental e incluso la agenda de medios (o agenda mediática). Diversos autores (Aruguete, 2009; Bouza, 2012; M.J. García, 2011; Corral, 2016; Maldonado y Casar, 2008; Petrone, 2009; Rubio, 2009; Stubager, 2015), han estudiado dichas agendas en el marco político.

\footnotetext{
"Visión de Futuro" Año 18, Volumen No 25 N 1, Enero - Junio 2021 - Pág 1 - 23 
De las diferentes agendas mencionadas, vamos a centrarnos en la agenda pública poniendo como marco de referencia dos aspectos: ¿qué son y cómo se forman las agendas?. En relación al primer punto, la agenda pública es definida como un listado de temas que la ciudadanía y distintos grupos de la sociedad, buscan posicionar para ser considerados como susceptibles de atención por parte de los representantes (Macassi, 1999; Maldonado y Casar, 2008; Petrone, 2009). En cuanto al segundo aspecto, Tamayo y Carrillo (2005), mencionan que un camino para la formación de la agenda pública es a través de encuestas de opinión sobre los problemas o temas que la gente considera importantes para resolver por sus representantes. Al respecto, Petrone (2009) menciona que la proporción o porcentajes más altos obtenidos en dichas encuestas, son los temas que deberán tener mayor notoriedad en la agenda pública.

Al formar la agenda pública, el número de asuntos mencionados por el ciudadano cuando se les pregunta: ¿Cuál piensa usted que es el problema más importante que ha de afrontar hoy el país? McCombs y Evatt (1995), mencionan que la lista es por naturaleza muy limitada, rara vez supera los cinco o siete asuntos. Esta limitante es posiblemente un factor importante sobre el poder de los medios para incluir más temas en la agenda.

Los asuntos de la agenda pública utilizada en la presente investigación, fueron tomados de un trabajo sobre temas preelectorales en el período 2011-2012 en México que realizó el autor Corral (2016).

Una vez expuesto lo que se entiende por la agenda, que es la entidad considerada como causas en la metodología de efectos olvidados, vamos a presentar la segunda entidad considerada como los efectos que son las actitudes políticas que el ciudadano adopta.

\section{Las actitudes políticas (una aproximación)}

Para poder establecer el significado de las actitudes políticas del ciudadano, es conveniente aclarar algunos términos. Mateos (2004), menciona que una actitud es un conjunto de creencias enfocadas hacia un objeto en particular o situación, y proporcionan una respuesta favorable o desfavorable que facilita la predisposición de un individuo. En particular si ese objeto es la política o el sistema político que tiene un país o nación, entonces podemos hablar de actitudes políticas.

No obstante, para comprender más a fondo el significado de las actitudes políticas, es necesario ubicarlas bajo la definición de cultura política.

El estudio de la cultura política no es nuevo y se remonta a mediados del siglo pasado. En los años sesenta, con el trabajo realizado por Almond y Verba, se establece una primera definición sosteniendo que: "la cultura política de una nación es una particular distribución de

\footnotetext{
“Visión de Futuro" Año 18, Volumen No 25 N 1, Enero - Junio 2021 - Pág 1 - 23

URL de la Revista: http://visiondefuturo.fce.unam.edu.ar/index.php/visiondefuturo/index

URL del Documento: https://visiondefuturo.fce.unam.edu.ar/index.php/visiondefuturo/issue/view/19

ISSN 1668 - 8708 - Versión en Línea

E-mail: revistacientifica@fce.unam.edu.ar
} 
los patrones de orientaciones hacia objetos políticos entre los miembros de una nación" (Mateos, 2004, p. 94).

En el presente documento, adoptamos como cultura política: "los valores, concepciones y actitudes que se orientan hacia el ámbito específicamente político, es decir, el conjunto de elementos que configuran la percepción subjetiva que tiene una población respecto del poder" (Peschard, 2019, p. 20). Lo que confirma que las actitudes son sólo un componente de la cultura política.

Mateos (2004), menciona que según la definición clásica de Almond y Verba, la operacionalización del concepto de cultura política permite dividirlo en tres tipos de orientaciones o dimensiones políticas: la cognitiva que se refiere a la información y el conocimiento que se tiene sobre el sistema político en su conjunto, sobre sus roles y actores en particular; la afectiva que se refiere a los sentimientos que se tienen respecto al sistema político y que pueden ser de apego o rechazo, y finalmente la evaluativa que se refiere a los juicios y opiniones que la población tiene acerca del sistema político. Cada una de estas dimensiones está compuesta a su vez por actitudes, creencias y valores políticos.

A partir de estas tres dimensiones, nos centramos en las actitudes que son propias de cada una de ellas. No obstante, debemos aclarar que los juicios y opiniones de la tercera dimensión evaluativa, incluyen la valoración de los individuos como sujetos participantes en la vida política. Por tanto, algunos autores españoles como Óscar García Luengo, hacen referencia a este componente como la dimensión conductual para designar actitudes políticas que muestren niveles de activismo o de participación cívica y política (Aruguete y Muñiz, 2012). Como consecuencia, para el presente trabajo se adopta el término conductual para la tercera dimensión. Cabe mencionar que la participación puede darse a diferentes niveles: desde ejercer el derecho que tiene todo ciudadano en votar, hasta realizar o tener responsabilidades específicas dentro de un partido político. Esta actitud participativa dentro de la dimensión conductual, se tomará en cuenta en nuestro modelo.

Dentro de la dimensión afectiva, una actitud incorporada en este estudio, es la confianza que vincula a los ciudadanos con las instituciones diseñadas para representar sus intereses (Tronco, 2012). Esta actitud de confianza es otra a tomar en cuenta en nuestro estudio para los gobernantes, partidos políticos e instituciones.

Finalmente incorporamos al presente trabajo, dentro de la dimensión cognitiva, la actitud de interés sobre temas políticos. La politóloga Pippa Norris afirma que las personas expuestas a medios de información y a las campañas electorales, están mejor documentadas en términos políticos y son personas que confían en el gobierno y en el sistema político, siendo más participativas en términos electorales (García, 2005). A esta postura, Norris (2001) le ha

\footnotetext{
“Visión de Futuro" Año 18, Volumen No 25 N 1, Enero - Junio 2021 - Pág 1 - 23

URL de la Revista: http://visiondefuturo.fce.unam.edu.ar/index.php/visiondefuturo/index

URL del Documento: https://visiondefuturo.fce.unam.edu.ar/index.php/visiondefuturo/issue/view/19

ISSN 1668 - 8708 - Versión en Línea

E-mail: revistacientifica@fce.unam.edu.ar
} 
llamado círculo virtuoso, donde, a largo plazo, los medios informativos sirven para que los más interesados tengan mayor conocimiento sobre estos temas.

Norris cita a Kurt y Gladys Lang (1966) para mencionar que antes del llamado círculo virtuoso, estos autores fueron los primeros en sugerir una postura contraria. Ellos mencionan que el exceso de exposición de la ciudadanía a los canales de información política tiene un efecto negativo, generando un sentimiento de desconexión hacia ella (Norris, 2001). Robinson (1976) fue el primero en popularizar esta relación con el término videomalestar, para describir ese efecto negativo que generan los medios informativos con sus audiencias para temas políticos.

Podemos decir que las actitudes políticas del ciudadano, además de verse influenciadas por los medios de comunicación, también se van conformando a través de diversos elementos en la vida de los individuos, como pueden ser factores del medioambiente, compañeros de trabajo, la familia, entre otros.

Una vez descrito el significado que le damos a la agenda pública y al término de actitudes políticas, presentamos una breve reflexión sobre la literatura existente aplicando la metodología elegida en este trabajo a diferentes áreas.

\section{Aplicación de la metodología en otros ámbitos}

La metodología utilizada en el presente estudio, está ubicada en el marco de la teoría de efectos olvidados. Carreón, Figueroa y Montoya (2017), mencionan que no somos más que seres humanos, inteligentes, pero no siempre fiables. Incluso ni con las más potentes computadoras para el manejo de la información, el riesgo del olvido no desaparecerá.

La literatura de esta metodología aplicada a temas políticos es prácticamente inexistente. No obstante, ha sido ampliamente utilizada en el estudio de fenómenos sociales, económicos, financieros, contables, entre otros.

Como muestra de lo anterior, podemos mencionar el trabajo de Gil Lafuente y Barcellos (2010) cuyo objetivo es fomentar el crecimiento sostenible de la empresa, a través de dos entidades. La primera compuesta por factores del medio ambiente de un país tal como su estabilidad política, nivel de corrupción, conflictos armados, entre otros. La segunda entidad está compuesta por elementos dentro de la empresa como la política ambiental de la misma, la ética profesional, el desarrollo de talentos, la viabilidad económica-financiera, entre otros.

Otro estudio es el de Salazar-Garza (2012), en el cual relaciona determinadas variables macroeconómicas y microeconómicas del mercado de divisas mexicano, que inciden en la determinación del tipo cambio de equilibrio peso-dólar.

\footnotetext{
"Visión de Futuro" Año 18, Volumen No 25 No 1, Enero - Junio 2021 - Pág 1 - 23 
Por otro lado, Álvarez (2016), en su trabajo presenta la incidencia de ciertas variables propuestas por un grupo de expertos en el riesgo cambiario que tienen las pequeñas y medianas empresas manufactureras.

En el ámbito del marketing, Tinto, Luna y Cisneros (2017), desarrollaron esta metodología para identificar efectos olvidados en el rescate de la imagen comercial de un grupo de artesanos en una provincia de Ecuador.

A pesar de todas estas aplicaciones y muchas más que se encuentran en la literatura, en el ámbito del marketing político, apenas pudimos identificar un trabajo con esta metodología realizado por Sarasola (2004). En dicho trabajo se parte de la hipótesis que la campaña política que precede a las elecciones, debe colocar a su candidato en posición de vencedor. Las causas fueron los diferentes medios de información y los efectos la percepción del candidato a través de sus atributos personales. El estudio mostró efectos olvidados no percibidos a simple vista por los entrevistados.

Analizando algunos rasgos característicos de los problemas que fueron resueltos con modelos propios de la teoría de efectos olvidados, podemos destacar como ventaja para utilizar esta metodología, la posibilidad de estudiar relaciones de causalidad en fenómenos complejos, donde en muchos casos su comportamiento es no lineal con variables o determinantes que tienen un grado de imprecisión acorde a un carácter sistémico, en donde existen interrelaciones mutuas que se condicionan e influyen entre sí para producir efectos.

En virtud de la escasa o nula literatura aplicando la teoría de efectos olvidados al marketing político, aplicamos estas herramientas no convencionales a este campo de estudio, en lugar de las técnicas tradicionales propias de la estadística. A continuación, se describe dicha metodología, seguida de una aplicación empírica.

\section{Metodología}

El concepto de incidencia, es utilizado o se halla asociado a la idea de un efecto de un conjunto de entidades (causas) sobre otro conjunto de entidades (efectos) o sobre sí mismo. De esta forma decimos por ejemplo, que la creación de empleos tiene una incidencia en la confianza de los políticos y a la vez, esto tiene una incidencia en el interés hacia la política.

Kaufmann y Gil Aluja (1988) mencionan que el concepto de incidencia se encuentra presente en todas las acciones de los seres vivos. A pesar de que la noción de incidencia es en sí misma simple, los autores mencionan que las incidencias al propagarse en una red de forma encadenada, con frecuencia de forma involuntaria, se omiten etapas y se olvidan conclusiones. Cada olvido trae como consecuencia efectos secundarios que van repercutiendo en toda la red de relaciones de incidencia en una especie de proceso combinatorio como lo menciona Gil Lafuente y Barcellos (2010). Estos olvidos pueden

\footnotetext{
"Visión de Futuro" Año 18, Volumen No 25 No 1, Enero - Junio 2021 - Pág 1 - 23

URL de la Revista: http://visiondefuturo.fce.unam.edu.ar/index.php/visiondefuturo/index

URL del Documento: https://visiondefuturo.fce.unam.edu.ar/index.php/visiondefuturo/issue/view/19

ISSN 1668 - 8708 - Versión en Línea

E-mail: revistacientifica@fce.unam.edu.ar
} 
conducir frecuentemente a efectos secundarios desfavorables en relación con las decisiones tomadas.

Para mostrar el funcionamiento de la teoría de los efectos olvidados, vamos a suponer que tenemos un conjunto de entidades (causas), que en el estudio empírico es una lista de temas de la agenda pública, sobre otro conjunto de entidades (efectos), que es también una lista de las actitudes políticas que experimenta el ciudadano, los cuales ambos conjuntos los representamos con las letras $\mathrm{P}$ (agenda pública) y $\mathrm{S}$ (actitudes políticas) respectivamente:

$$
\begin{aligned}
& P=\left\{p_{i} / i=1,2,3, \ldots n\right\} \text { (causas) } \\
& S=\left\{s_{j} / j=1,2,3, \ldots m\right\} \text { (efectos) }
\end{aligned}
$$

Decimos que hay una incidencia de $p_{i}$ en $s_{j}$ si la función característica de pertenencia de la pareja $\left(p_{i}, s_{j}\right)$ tiene una valuación en $[0,1]$. Recordemos que el concepto de valuación está ligado a una medición subjetiva, como lo menciona Gil Aluja (2002).

El grado de incidencia de cada pareja $\left(\mathrm{p}_{\mathrm{i}}, \mathrm{s}_{\mathrm{j}}\right)$ se puede expresar a través de una función:

$\mu:$ PXS $\rightarrow[0,1]$ tal que $\forall\left(p_{i}, s_{j}\right) \in P X S, \mu\left(p_{i}, s_{j}\right) \in[0,1]$

A la matriz formada por el conjunto de elementos valuados de cada elemento de $\mathrm{P}$ a cada elemento de $\mathrm{S}$, se le conoce como matriz de incidencias directas o de primera

\begin{tabular}{|c|c|c|c|c|c|}
\hline$\nearrow$ & $s_{1}$ & $\mathrm{~s}_{2}$ & $s_{3}$ & $\ldots$ & $\mathrm{S}_{\mathrm{m}}$ \\
\hline \multirow{3}{*}[D]{$=$} & $\mu\left(p_{1}, s_{1}\right)$ & $\mu\left(p_{1}, s_{2}\right)$ & $\mu\left(p_{1}, s_{3}\right)$ & & $\mu\left(p_{1}, s_{m}\right)$ \\
\hline & $\mu\left(p_{2}, s_{1}\right)$ & $\mu\left(p_{2}, s_{2}\right)$ & $\mu\left(p_{2}, s_{3}\right)$ & & $\mu\left(p_{2}, s_{m}\right)$ \\
\hline & & & & $\mu\left(p_{i}, s_{j}\right)$ & \\
\hline$p_{n}$ & $\mu\left(p_{n}, s_{1}\right)$ & $\mu\left(p_{n}, s_{2}\right)$ & $\mu\left(p_{n}, s_{3}\right)$ & & $\mu\left(p_{n}, s_{m}\right)$ \\
\hline
\end{tabular}
generación. Figura №1.

Figura $\mathrm{N}^{\circ}$ 1. Matriz de incidencias directas o de primera generación Fuente: Elaboración propia

La matriz [D], al ser valuadas cada entrada $\mu\left(p_{i}, s_{j}\right)$ en el intervalo $[0,1]$, en la medida en que exista una mayor incidencia, se aproximará al valor 1 y en la medida en que se valore una menor incidencia, se aproxima al valor 0 .

Si la matriz $[D]$ refleja las relaciones causa-efecto directas, es decir, de primera generación, para los objetivos que nos proponemos analizar, debemos obtener dos nuevas matrices de incidencias. Por un lado, la que refleje aquellas relaciones de incidencias dentro del conjunto de causas entre sí, y por el otro lado, una matriz de incidencias dentro del conjunto de efectos entre sí. Estas matrices por su naturaleza son cuadradas.

Sea $[A]=$ PXP la matriz de incidencias de las causas entre sí.

$[A]=\left\{\mu\left(p_{i}, p_{j}\right) \in[0,1] / i, j=1,2,3, \ldots n\right\}$

\footnotetext{
"Visión de Futuro" Año 18, Volumen $\mathrm{N}^{0} 25$ No 1, Enero - Junio 2021 - Pág 1 - 23

URL de la Revista: http://visiondefuturo.fce.unam.edu.ar/index.php/visiondefuturo/index

URL del Documento: https://visiondefuturo.fce.unam.edu.ar/index.php/visiondefuturo/issue/view/19 
Sea $[\mathrm{B}]=$ SXS la matriz de incidencias de los efectos entre sí.

$[B]=\left\{\mu\left(s_{i}, s_{j}\right) \in[0,1] / i, j=1,2,3, \ldots m\right\}$

Donde $\mu\left(\mathrm{p}_{\mathrm{i}}, \mathrm{p}_{\mathrm{j}}\right)$ y $\mu\left(\mathrm{s}_{\mathrm{i}}, \mathrm{s}_{\mathrm{j}}\right)$ son los valores de la función característica de pertenencia.

Por naturaleza, $[\mathrm{A}]$ y $[\mathrm{B}]$ coinciden en que ambas son reflexivas, es decir, en la diagonal, $\mu\left(p_{i}, p_{i}\right)=1$ y $\mu\left(s_{j}, s_{j}\right)=1$ Esto significa que cada elemento tiene la máxima incidencia consigo mismo.

Por otro lado, las matrices $[\mathrm{A}]$ y $[\mathrm{B}]$ no tienen que ser matrices simétricas. Esto significa

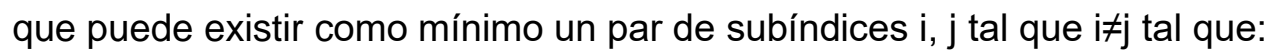

$$
\mu\left(p_{i}, p_{j}\right) \neq \mu\left(p_{j}, p_{i}\right) \text { y } \mu\left(s_{i}, s_{j}\right) \neq \mu\left(s_{j}, s_{i}\right)
$$

Por ejemplo, si la creación de empleos incide en la confianza de los políticos en un cierto nivel, no necesariamente la confianza de los políticos tiene incidencia con la creación de empleos y si así fuera, no tiene por qué tener el mismo nivel de incidencia.

Una vez construidas las tres matrices de incidencias $[D],[A]$ y $[B]$, como menciona Kaufmann y Gil Aluja (1988), la operación matemática que permite conocer la incidencia de [A] sobre [D] y de [D] sobre [B] es la composición máximo-mínimo o simplemente max-min. Dicha composición se expresa como:

$$
[\mathrm{A}] \circ[\mathrm{D}] \circ[\mathrm{B}]=\left[\mathrm{D}^{*}\right]
$$

Teniendo cuidado con los tamaños de las matrices al hacer las operaciones, la nueva matriz [ $\left.\mathrm{D}^{\star}\right]$ recoge las incidencias entre causas y efectos de segundo orden y es llamada matriz de efectos de segunda generación, figura $\mathrm{N}^{\circ} 2$.

Gil Lafuente y Barcellos (2010), mencionan que esta matriz capta las relaciones causales iniciales afectadas por la posible incidencia interpuesta de alguna causa o algún

\begin{tabular}{|c|c|c|c|}
\hline & $p_{1}$ & $\mathrm{p}_{2}$ & $p_{n}$ \\
\hline & 1 & $\mu\left(p_{1}, p_{2}\right)$ & $\mu\left(p_{1}, p_{n}\right)$ \\
\hline & $\mu\left(p_{2}, p_{1}\right)$ & 1 & $\mu\left(p_{2}, p_{n}\right)$ \\
\hline & $\mu\left(p_{n}, p_{1}\right)$ & $\mu\left(p_{n}, p_{2}\right)$ & 1 \\
\hline
\end{tabular}
efecto.

\begin{tabular}{|c|c|c|c|}
\hline$\lambda$ & $s_{1}$ & $\mathrm{~s}_{2}$ & $\mathrm{~s}_{\mathrm{m}}$ \\
\hline$p_{1}$ & $\mu\left(p_{1}, s_{1}\right)$ & $\mu\left(p_{1}, s_{2}\right)$ & $\mu\left(p_{1}, s_{m}\right)$ \\
\hline$p_{2}$ & $\mu\left(p_{2}, s_{1}\right)$ & $\mu\left(p_{2}, s_{2}\right)$ & $\mu\left(p_{2}, s_{m}\right)$ \\
\hline & & & \\
\hline $\mathrm{p}$ & $\mu\left(p_{n}, s_{1}\right)$ & $\mu\left(p_{n}, s_{2}\right)$ & $\mu\left(p_{n}, s_{m}\right)$ \\
\hline
\end{tabular}

[A]
[D]

\begin{tabular}{|c|c|c|c|}
\hline & $\mathrm{s}_{1}$ & $s_{2}$ & $\mathrm{~s}_{\mathrm{m}}$ \\
\hline$p_{1}$ & $\mu^{*}\left(p_{1}, s_{1}\right)$ & $\mu^{*}\left(p_{1}, s_{2}\right)$ & $\mu^{*}\left(p_{1}, s_{m}\right)$ \\
\hline & $\mu^{*}\left(p_{2}, s_{1}\right)$ & $\mu^{*}\left(p_{2}, s_{2}\right)$ & $\mu^{\star}\left(p_{2}, s_{m}\right)$ \\
\hline & $\mu^{*}\left(p_{n}, s_{1}\right)$ & $\mu^{*}\left(p_{n}, s_{2}\right)$ & $\mu^{*}\left(p_{n}, s_{m}\right)$ \\
\hline
\end{tabular}

\begin{tabular}{c|c|c|c|c|}
\multicolumn{1}{c}{$c_{1}$} & $s_{1}$ & $s_{2}$ & $\ldots$ & $s_{m}$ \\
\cline { 2 - 5 }$s_{1}$ & 1 & $\mu\left(s_{1}, s_{2}\right)$ & & $\mu\left(s_{1}, s_{m}\right)$ \\
\cline { 2 - 5 }$s_{2}$ & $\mu\left(s_{2}, s_{1}\right)$ & 1 & & $\mu\left(s_{2}, s_{m}\right)$ \\
\cline { 2 - 5 } & & & & \\
\cline { 2 - 5 }$s_{m}$ & $\mu\left(s_{m}, s_{1}\right)$ & $\mu\left(s_{m}, s_{2}\right)$ & & 1 \\
\cline { 2 - 5 } & \multicolumn{5}{c}{$[C]$}
\end{tabular}

$\left[\mathrm{D}^{*}\right]$

Figura $\mathrm{N}^{\circ}$ 2. [ $\left.\mathrm{D}^{\star}\right]$ Matriz de efectos de segunda generación Fuente: Elaboración propia

\footnotetext{
“Visión de Futuro" Año 18, Volumen No 25 N 1, Enero - Junio 2021 - Pág 1 - 23

URL de la Revista: http://visiondefuturo.fce.unam.edu.ar/index.php/visiondefuturo/index

URL del Documento: https://visiondefuturo.fce.unam.edu.ar/index.php/visiondefuturo/issue/view/19

ISSN 1668 - 8708 - Versión en Línea

E-mail: revistacientifica@fce.unam.edu.ar
} 
Continuando con esta breve presentación de la metodología de la teoría de los efectos olvidados, Kaufmann y Gil Aluja (1988) proponen para identificar si existen dichos efectos, obtener la diferencia aritmética, celda por celda, entre la matriz de segunda generación $\left[\mathrm{D}^{\star}\right]$ y la matriz de incidencias directas o de primera generación [D]. Si las diferencias son cero o muy cerca de cero, esto significa que no hay efectos olvidados, pero si las diferencias se alejan del valor cero, esto permitirá conocer el grado en que algunas relaciones de causalidad han sido olvidadas o se dan por obvias.

Esta última matriz $[\mathrm{O}]=\left[\mathrm{D}^{\star}\right]-[\mathrm{D}]$ muestra los efectos olvidados. Figura $\mathrm{N}^{\circ} 3$

\begin{tabular}{|c|c|c|c|c|}
\hline$\nearrow$ & $\mathrm{s}_{1}$ & $\mathrm{~s}_{2}$ & $\ldots$ & $\mathrm{s}_{\mathrm{m}}$ \\
\hline$p_{1}$ & $\mu^{*}\left(p_{1}, s_{1}\right)-\mu\left(p_{1}, s_{1}\right)$ & $\mu^{*}\left(p_{1}, s_{2}\right)-\mu\left(p_{1}, s_{2}\right)$ & & $\mu^{*}\left(p_{1}, s_{m}\right)-\mu\left(p_{1}, s_{m}\right)$ \\
\hline$p_{2}$ & $\mu^{*}\left(p_{2}, s_{1}\right)-\mu\left(p_{2}, s_{1}\right)$ & $\mu^{*}\left(p_{2}, s_{2}\right)-\mu\left(p_{2}, s_{2}\right)$ & & $\mu^{*}\left(p_{2}, s_{m}\right)-\mu\left(p_{2}, s_{m}\right)$ \\
\hline$p_{n}$ & $\mu^{*}\left(p_{n}, s_{1}\right)-\mu\left(p_{n}, s_{1}\right)$ & $\mu^{*}\left(p_{n}, s_{2}\right)-\mu\left(p_{n}, s_{2}\right)$ & & $\mu^{*}\left(p_{n}, s_{m}\right)-\mu\left(p_{n}, s_{m}\right)$ \\
\hline
\end{tabular}

Figura $\mathbf{N}^{\circ}$ 3. Matriz de efectos olvidados

Fuente: Elaboración propia

Analizando esta última matriz, podemos identificar aquellos elementos cuya valuación es más elevada: entre más grande sea dicho valor, mayor es el grado de olvido entre $p_{i}$ y $s_{j}$ producido en la matriz de incidencia de primer orden. Rodríguez, Ramírez y Díaz (2008) mencionan que esta matriz obtenida pone al descubierto efectos que los individuos o expertos no toman en cuenta al valuar las relaciones entre las entidades que se analizan. En varios de los estudios realizados con esta metodología, se tiene la costumbre de mencionar que con un valor de 0.4 o más, es un criterio bueno para analizar los efectos olvidados de esa celda. No obstante, este criterio puede ser flexible en virtud de las entidades analizadas.

\section{Efectos olvidados entre la agenda pública y las actitudes políticas en México}

Con la metodología explicada en el apartado anterior, vamos a ilustrar la existencia de efectos olvidados entre los temas que son comunes en el ciudadano y la forma en que estos asuntos inciden en las actitudes que experimenta el individuo en torno a ciertos componentes del sistema político en la zona poniente metropolitana de la Ciudad de México.

Para iniciar, se tomó como referencia la agenda pública en México de un estudio preelectoral 2011-2012 elaborado por Corral (2016). En esa investigación se diseñó la agenda pública a través de estudios de opinión, elaborados por la empresa Mercaei y publicados por la presidencia de la República en su página de Internet (El gobierno actual eliminó la liga de Internet). Dichas encuestas se realizaron considerando un nivel de confianza del $95 \%$ y un error máximo que no es más del 3\%.

\footnotetext{
"Visión de Futuro" Año 18, Volumen No 25 No 1, Enero - Junio 2021 - Pág 1 - 23

URL de la Revista: http://visiondefuturo.fce.unam.edu.ar/index.php/visiondefuturo/index

URL del Documento: https://visiondefuturo.fce.unam.edu.ar/index.php/visiondefuturo/issue/view/19

ISSN 1668 - 8708 - Versión en Línea

E-mail: revistacientifica@fce.unam.edu.ar
} 
Para este trabajo, que coincide con el período preelectoral 2017-2018 se trató de buscar la misma información. La empresa Mercaei ya no volvió a realizar otro estudio similar e incluso se solicitó a la presidencia de la República la agenda pública actualizada, a través de su página oficial y no hubo respuesta.

Por lo anterior, se optó por tomar la mayoría de los temas principales de la agenda pública que usó Corral (2016), asumiendo que no hay grandes diferencias en un período tan corto como lo es del año 2012 al 2018.

McCombs y Evatt (1995) mencionan que una agenda no puede considerarse sólo como una lista de temas de importancia, sino más bien debe ser considerada como un modo de ordenar lo que es importante, por tanto en nuestro caso, respetamos el orden de los temas seleccionados de la agenda de referencia, excepto por el tema de educación que se añadió al final de la lista, por considerar éste asunto importante en base al estudio Panel 2012 de la Encuesta de Cultura Política y Prácticas Ciudadanas (ENCUP) (http://www.encup.gob.mx/). Cabe aclarar que la agenda utilizada, no tiene carácter exhaustivo y además podría ser distinta según el país y la época.

En la Tabla $\mathrm{N}^{\circ} 1$ se presenta la lista de los 12 temas de la agenda pública utilizada en el estudio que actúan en el modelo como causas.

$$
P=\left\{p_{1}, p_{2}, p_{3}, p_{4}, p_{5}, p_{6}, p_{7}, p_{8}, p_{9}, p_{10}, p_{11}, p_{12}\right\}
$$

Tabla N 1. Temas de la Agenda Pública

\begin{tabular}{|c|l|c|l|}
\hline$p_{1}$ & La inseguridad & $p_{7}$ & La corrupción \\
\hline$p_{2}$ & El desempleo & $p_{8}$ & La vida interna en los partidos políticos \\
\hline$p_{3}$ & La economía & $p_{9}$ & Catástrofe o desgracia natural \\
\hline$p_{4}$ & $\begin{array}{l}\text { El crimen organizado y el } \\
\text { narcotráfico }\end{array}$ & $p_{10}$ & $\begin{array}{l}\text { Las elecciones de candidatos a puestos } \\
\text { políticos }\end{array}$ \\
\hline$p_{5}$ & La pobreza & $p_{11}$ & Las reformas, leyes y decretos \\
\hline$p_{6}$ & La Eficacia Gubernamental & $p_{12}$ & La educación \\
\hline
\end{tabular}

Fuente: Elaboración Propia adaptado de Corral (2016)

En relación a las actitudes políticas, se determinaron cinco de ellas que incluyen las tres orientaciones o dimensiones de la cultura política que señala García Luengo citado en Aruguete y Muñiz (2012), estas son: la dimensión afectiva, cognitiva y conductual.

En la Tabla $N^{\circ} 2$ se presenta la lista de actitudes políticas que actúan en el modelo como efectos a los temas de la agenda pública.

$$
\mathrm{S}=\left\{\mathrm{s}_{1}, \mathrm{~s}_{2}, \mathrm{~s}_{3}, \mathrm{~s}_{4}, \mathrm{~s}_{5}\right\}
$$

\footnotetext{
"Visión de Futuro" Año 18, Volumen No 25 No 1, Enero - Junio 2021 - Pág 1 - 23 
Tabla $N^{\circ}$ 2. Lista de actitudes políticas

\begin{tabular}{|c|c|l|}
\hline \multirow{3}{*}{ Dimensión afectiva } & $\mathrm{S}_{1}$ & Confianza en los gobernantes en general \\
\cline { 2 - 4 } & $\mathrm{S}_{2}$ & Confianza en los partidos políticos \\
\cline { 2 - 4 } Dimensión cognitiva & $\mathrm{S}_{3}$ & $\begin{array}{l}\text { Confianza en las Instituciones (cámaras de } \\
\text { representantes e Instituciones como el INE, Tribunal } \\
\text { electoral, etc. }\end{array}$ \\
\cline { 2 - 4 } Dimensión conductual & $\mathrm{S}_{4}$ & $\begin{array}{l}\text { Interés por la política (curiosidad por conocer asuntos } \\
\text { relacionados con la política) }\end{array}$ \\
\cline { 2 - 4 } & $\mathrm{S}_{5}$ & $\begin{array}{l}\text { Intención de participar en la política (a través del voto u } \\
\text { otros medios no convencionales tales como } \\
\text { manifestaciones, movilizaciones) }\end{array}$ \\
\hline
\end{tabular}

Fuente: Elaboración propia adaptado de Aruguete y Muñiz (2012)

Una vez definidos los elementos de P como causas y S como efectos, se realizaron 120 entrevistas personales a ciudadanos en la zona metropolitana poniente de la Ciudad de México. La edad se determinó entre 40 y 80 años de edad ya que a partir de 40 años, los ciudadanos han visto transitar una buena parte de la política contemporánea de México tomando en cuenta que, desde finales del siglo pasado se materializó una lucha más abierta entre los partidos políticos, dando lugar a la alternancia. La muestra se formó con $50 \%$ hombres y $50 \%$ mujeres; todos con nivel de estudios igual o superior a bachillerato 0 preparatoria.

Antes de iniciar la entrevista, se aclaró el significado del término incidencia, como una valuación subjetiva de causa y efecto entre los elementos a valuar.

La valuación de cada celda entre las causas y los efectos, se llevó a cabo con la siguiente escala endecadaria de 11 puntos.

0 : sin incidencia

0.1 : prácticamente sin incidencia

0.2 : casi sin incidencia

0.3: muy débil incidencia

0.4: débil incidencia

0.5: mediana incidencia

0.6: incidencia sensible

0.7: bastante incidencia

0.8: fuerte incidencia

0.9: muy fuerte incidencia

1: la mayor incidencia

Antes de iniciar la aplicación de la metodología de los efectos olvidados, es necesario la agregación de las valuaciones emitidas por todos los ciudadanos entrevistados que emitieron sus valuaciones en relación al tema que estamos tratando.

\footnotetext{
"Visión de Futuro" Año 18, Volumen No 25 No 1, Enero - Junio 2021 - Pág 1 - 23 
Para lograr dicha agregación, en el ámbito de la incertidumbre Kaufmann y Gil Aluja (1993), definen el expertizaje como un proceso de consulta a un grupo determinado de expertos (en este caso a los 120 ciudadanos entrevistados) donde a través de un proceso relativamente sencillo, se obtiene un valor que representa la opinión agregada de los ciudadanos consultados para cada una de las incidencias en nuestro modelo.

A manera de ejemplo, se muestra en la Tabla $N^{\circ} 3$, como se obtuvo la opinión agregada de la incidencia entre el tema de La inseguridad con la Intención de participar en la política $\left(p_{1} \rightarrow s_{5}\right)$

Paso 1. Estadísticas o frecuencia absoluta. Se cuenta el número de veces que los ciudadanos han dado la misma valuación de incidencia utilizando valores de 0 a 1 (valuación endecadaria).

Paso 2. Frecuencia relativa o normalizada. Basta con dividir del cuadro de frecuencia absoluta, cada uno de los valores por el número total de ciudadanos, en este caso por 120 .

Paso 3. Acumulación de frecuencias complementarias. Acumulamos las frecuencias relativas empezando la agregación de abajo hacia arriba, es decir, de 1 hasta 0 , obteniendo de esta forma un expertón.

Gil Aluja (2002), menciona que un expertón así representado, es el número incierto que constituye la agregación de opiniones cuantificables en cifras numéricas manteniendo toda la información y permitiendo cualquier operación posterior, sea lineal o no lineal; situación que al trabajar con medias, perdemos información antes de que fuese necesaria.

Paso 4. A continuación se suma la columna de acumulación de frecuencias sin considerar el 1 en el grado de presunción igual a cero. La suma es 4.883.

Paso 5. Finalmente, el valor obtenido de la suma anterior, se divide entre 10 que es el número de niveles que forman el grado de presunción considerando desde 0.1 hasta 1 . En este caso es: $4.883 / 10=0.4883=0.5$ con un decimal.

El valor de 0.5 representa la opinión agregada de los 120 ciudadanos respecto a la incidencia que tiene La inseguridad con respecto a la Intención de participar en la política. Ver Tabla N³.

\footnotetext{
“Visión de Futuro" Año 18, Volumen No 25 N 1, Enero - Junio 2021 - Pág 1 - 23 
Tabla $N^{\circ}$ 3. Expertizaje: La inseguridad y La intención de participar en la política

\begin{tabular}{|c|c|c|c|}
\hline $\begin{array}{c}\left(\mathrm{p}_{1}, \mathrm{~S}_{5}\right) \\
\begin{array}{c}\text { Grado de } \\
\text { presunción }\end{array}\end{array}$ & Frecuencia absoluta & Frecuencia relativa & $\begin{array}{c}\text { Acumulación de } \\
\text { frecuencias }\end{array}$ \\
\hline 0 & 19 & 0.158 & 1.000 \\
\hline 0.1 & 5 & 0.042 & 0.842 \\
\hline 0.2 & 5 & 0.042 & 0.800 \\
\hline 0.3 & 11 & 0.092 & 0.758 \\
\hline 0.4 & 10 & 0.083 & 0.667 \\
\hline 0.5 & 19 & 0.158 & 0.583 \\
\hline 0.6 & 9 & 0.075 & 0.425 \\
\hline 0.7 & 12 & 0.100 & 0.350 \\
\hline 0.8 & 14 & 0.117 & 0.250 \\
\hline 0.9 & 7 & 0.058 & 0.133 \\
\hline 1 & 9 & 0.075 & 0.075 \\
\hline Total & 120 & 1.000 & 4.883 \\
\hline & & opinión agregada & 0.5 \\
\hline
\end{tabular}

Fuente: Elaboración propia

Con este procedimiento, se forma cada celda de la matriz agregada [D] de incidencias directas con la información proporcionada por los 120 ciudadanos, y las cifras en dichas celdas son los niveles de incidencias directas o de primer orden. Matriz $\mathrm{N}^{\circ} 1$

Matriz $\mathrm{N}^{\circ}$ 1. Matriz agregada [D] de incidencias directas

\begin{tabular}{|c|c|c|c|c|c|}
\hline $\begin{array}{c}\text { [D] efectos } \\
\text { causas } r\end{array}$ & $\begin{array}{c}\text { Confianza en los } \\
\text { gobernantes en } \\
\text { general }\end{array}$ & $\begin{array}{l}\text { Confianza en los } \\
\text { partidos políticos }\end{array}$ & $\begin{array}{c}\text { Confianza en las } \\
\text { Instituciones }\end{array}$ & $\begin{array}{c}\text { Interés por la } \\
\text { política }\end{array}$ & $\begin{array}{c}\text { Intención de } \\
\text { participar en la } \\
\text { política }\end{array}$ \\
\hline La inseguridad & 0,7 & 0,5 & 0,5 & 0,7 & 0,5 \\
\hline El desempleo & 0,7 & 0,5 & 0,5 & 0,7 & 0,5 \\
\hline La economía & 0,7 & 0,5 & 0,5 & 0,7 & 0,8 \\
\hline $\begin{array}{c}\text { El crimen organizado } \\
\text { y el narcotráfico }\end{array}$ & 0,7 & 0,7 & 0,5 & 0,7 & 0,5 \\
\hline La pobreza & 0,7 & 0,5 & 0,5 & 0,7 & 0,7 \\
\hline $\begin{array}{c}\text { La Eficacia } \\
\text { Gubernamental }\end{array}$ & 0,7 & 0,7 & 0,7 & 0,7 & 0,7 \\
\hline La corrupción & 0,7 & 0,8 & 0,7 & 0,8 & 0,7 \\
\hline $\begin{array}{l}\text { La vida interna en los } \\
\text { partidos políticos }\end{array}$ & 0,5 & 0,7 & 0,7 & 0,7 & 0,5 \\
\hline $\begin{array}{c}\text { Catástrofe o } \\
\text { desgracia natural }\end{array}$ & 0,3 & 0,3 & 0,3 & 0,5 & 0,5 \\
\hline $\begin{array}{c}\text { Las elecciones de } \\
\text { candidatos a puestos } \\
\text { públicos }\end{array}$ & 0,7 & 0,7 & 0,7 & 0,7 & 0,7 \\
\hline $\begin{array}{c}\text { Las reformas, leyes o } \\
\text { decretos }\end{array}$ & 0,7 & 0,7 & 0,7 & 0,7 & 0,7 \\
\hline La educación & 0,7 & 0,7 & 0,7 & 0,7 & 0,8 \\
\hline
\end{tabular}

Fuente: Elaboración propia en base a las entrevistas y utilizando expertizaje

El objetivo que nos planteamos en esta investigación es, aplicar la teoría de los efectos olvidados para identificar la existencia de relaciones que con frecuencia se omiten al no tener en cuenta los efectos ocasionados por las causas entre sí y los efectos entre sí.

Para ello, los mismos ciudadanos entrevistados, establecieron las incidencias entre las causas entre sí y los efectos entre sí. Dichas matrices agregadas son la Matriz $\mathrm{N}^{\circ} 2$ y Matriz $N^{\circ} 3$ respectivamente.

\footnotetext{
"Visión de Futuro" Año 18, Volumen $N^{0} 25$ No 1, Enero - Junio 2021 - Pág 1 - 23

URL de la Revista: http://visiondefuturo.fce.unam.edu.ar/index.php/visiondefuturo/index

URL del Documento: https://visiondefuturo.fce.unam.edu.ar/index.php/visiondefuturo/issue/view/19

ISSN 1668 - 8708 - Versión en Línea

E-mail: revistacientifica@fce.unam.edu.ar
} 
Matriz $\mathrm{N}^{\circ}$ 2. Matriz agregada [A] de incidencias entre temas de la agenda pública

\begin{tabular}{|c|c|c|c|c|c|c|c|c|c|c|c|c|}
\hline $\begin{array}{l}{[\mathrm{A}] \text { causas }} \\
\text { causas } \succ\end{array}$ & $\begin{array}{c}\text { La } \\
\text { inseguridad } \\
\end{array}$ & $\begin{array}{c}\text { El } \\
\text { desempleo } \\
\end{array}$ & $\begin{array}{c}\text { La } \\
\text { economía }\end{array}$ & \begin{tabular}{|c|} 
El crimen \\
organizado y \\
el \\
narcotráfico \\
\end{tabular} & $\begin{array}{c}\text { La } \\
\text { pobreza }\end{array}$ & $\begin{array}{c}\text { La Eficacia } \\
\text { Gubernamental }\end{array}$ & $\begin{array}{c}\text { La } \\
\text { corrupción }\end{array}$ & $\begin{array}{c}\text { La vida } \\
\text { interna en } \\
\text { los partidos } \\
\text { políticos } \\
\end{array}$ & $\begin{array}{c}\text { Catástrofe } 0 \\
\text { desgracia } \\
\text { natural }\end{array}$ & \begin{tabular}{|c|} 
Las \\
elecciones de \\
candidatos a \\
puestos \\
públicos \\
\end{tabular} & $\begin{array}{l}\text { Las } \\
\text { reformas, } \\
\text { leyes } 0 \\
\text { decretos }\end{array}$ & $\begin{array}{c}\text { La } \\
\text { educación }\end{array}$ \\
\hline La inseguridad & 1 & 0,8 & 0,8 & 0,9 & 0,7 & 0,7 & 0,9 & 0,5 & 0,2 & 0,7 & 0,5 & 0,7 \\
\hline El desempleo & 0,8 & 1 & 0,9 & 0,9 & 0,9 & 0,7 & 0,8 & 0,3 & 0,2 & 0,5 & 0,7 & 0,7 \\
\hline La economía & 0,8 & 0,9 & 1 & 0,9 & 0,8 & 0,7 & 0,8 & 0,7 & 0,3 & 0,7 & 0,7 & 0,8 \\
\hline $\begin{array}{c}\text { El crimen } \\
\text { organizado y el } \\
\text { narcotráfico } \\
\end{array}$ & 1 & 0,8 & 0,8 & 1 & 0,8 & 0,7 & 0,9 & 0,7 & 0,1 & 0,8 & 0,7 & 0,7 \\
\hline La pobreza & 0,8 & 0,9 & 0,9 & 0,9 & 1 & 0,5 & 0,8 & 0,5 & 0,3 & 0,7 & 0,5 & 0,8 \\
\hline $\begin{array}{c}\text { La Eficacia } \\
\text { Gubernamental }\end{array}$ & 0,8 & 0,7 & 0,9 & 0,8 & 0,8 & 1 & 0,8 & 0,7 & 0,2 & 0,8 & 0,8 & 0,8 \\
\hline La corrupción & 0,9 & 0,8 & 0,8 & 0,9 & 0,8 & 0,8 & 1 & 0,8 & 0,2 & 0,9 & 0,8 & 0,7 \\
\hline $\begin{array}{c}\text { La vida interna en } \\
\text { los partidos } \\
\text { políticos }\end{array}$ & 0,3 & 0,5 & 0,5 & 0,7 & 0,7 & 0,8 & 0,8 & 1 & 0,2 & 0,8 & 0,7 & 0,5 \\
\hline $\begin{array}{c}\text { Catástrofe } 0 \\
\text { degracia natural }\end{array}$ & 0,3 & 0,5 & 0,7 & 0,2 & 0,5 & 0,3 & 0,5 & 0,2 & 1 & 0,2 & 0,3 & 0,2 \\
\hline $\begin{array}{c}\text { Las elecciones de } \\
\text { candidatos a } \\
\text { puestos públicos }\end{array}$ & 0,5 & 0,5 & 0,7 & 0,7 & 0,7 & 0,8 & 0,8 & 0,8 & 0,2 & 1 & 0,5 & 0,5 \\
\hline $\begin{array}{c}\text { Las reformas, } \\
\text { leyes o decretos }\end{array}$ & 0,7 & 0,7 & 0,8 & 0,7 & 0,7 & 0,8 & 0,7 & 0,7 & 0,3 & 0,7 & 1 & 0,8 \\
\hline La educación & 0,7 & 0,8 & 0,8 & 0,8 & 0,8 & 0,7 & 0,8 & 0,7 & 0,3 & 0,7 & 0,7 & 1 \\
\hline
\end{tabular}

Fuente: Elaboración propia en base a las entrevistas y utilizando expertizaje

Matriz $\mathrm{N}^{\circ}$ 3. Matriz agregada $[\mathrm{B}]$ de incidencias entre actitudes

\begin{tabular}{|c|c|c|c|c|c|}
\hline $\begin{array}{c}\text { [ B ] efectos } \\
\text { efectos }\end{array}$ & $\begin{array}{c}\text { Confianza en los } \\
\text { gobernantes en } \\
\text { general }\end{array}$ & $\begin{array}{c}\text { Confianza en los } \\
\text { partidos políticos }\end{array}$ & $\begin{array}{c}\text { Confianza en las } \\
\text { Instituciones }\end{array}$ & $\begin{array}{c}\text { Interés por la } \\
\text { política }\end{array}$ & $\begin{array}{c}\text { Intención de } \\
\text { participar en la } \\
\text { política }\end{array}$ \\
\hline $\begin{array}{c}\text { Confianza en los } \\
\text { gobernantes en } \\
\text { general }\end{array}$ & 1 & 0,8 & 0,7 & 0,7 & 0,7 \\
\hline $\begin{array}{c}\text { Confianza en los } \\
\text { partidos políticos }\end{array}$ & 0,7 & 1 & 0,7 & 0,7 & 0,7 \\
\hline $\begin{array}{c}\text { Confianza en las } \\
\text { Instituciones }\end{array}$ & 0,7 & 0,7 & 1 & 0,7 & 0,7 \\
\hline $\begin{array}{c}\text { Interés por la } \\
\text { política }\end{array}$ & 0,5 & 0,5 & 0,5 & 1 & 0,8 \\
\hline $\begin{array}{c}\text { Intención de } \\
\text { participar en la } \\
\text { política }\end{array}$ & 0,5 & 0,3 & 0,5 & & \\
\hline
\end{tabular}

Fuente: Elaboración propia en base a las entrevistas y utilizando expertizaje

Una vez obtenidas las matrices [D], $[\mathrm{A}]$ y [B], como lo menciona Kaufmann y Gil Aluja (1988), la operación matemática que permite conocer la incidencia de [A] sobre [D] y de [D] sobre $[\mathrm{B}]$ es la composición máximo-mínimo o max-min y se expresa:

\footnotetext{
"Visión de Futuro" Año 18, Volumen No 25 N 1, Enero - Junio 2021 - Pág 1 - 23

URL de la Revista: http://visiondefuturo.fce.unam.edu.ar/index.php/visiondefuturo/index

URL del Documento: https://visiondefuturo.fce.unam.edu.ar/index.php/visiondefuturo/issue/view/19

ISSN 1668 - 8708 - Versión en Línea

E-mail: revistacientifica@fce.unam.edu.ar
} 


$$
[\mathrm{A}] \circ[\mathrm{D}] \circ[\mathrm{B}]=\left[\mathrm{D}^{*}\right]
$$

El programa que se utilizó para realizar las operaciones entre las matrices mencionadas, fue elaborado especialmente para trabajar modelos basados en la matemática de la incertidumbre para recuperar los Efectos Olvidados en relaciones de incidencia. ${ }^{1}$

Kaufmann y Gil Aluja (1988) Ilaman a [D*] matriz de incidencias de segundo orden y expresa los efectos de $[\mathrm{A}]$ y de $[\mathrm{B}]$ conjuntamente. Matriz $\mathrm{N}^{\circ} 4$.

Matriz $\mathbf{N}^{\circ}$ 4. Matriz de incidencias de segundo orden [ $\left.\mathrm{D}^{\star}\right]$

\begin{tabular}{|c|c|c|c|c|c|}
\hline $\begin{array}{c}{\left[\mathrm{D}^{*}\right]=[\mathrm{A}] \text { o [D] o [B] }} \\
\text { causas } \rightarrow \text { efectos }\end{array}$ & $\begin{array}{c}\text { Confianza en los } \\
\text { gobernantes en } \\
\text { general }\end{array}$ & $\begin{array}{c}\text { Confianza en los } \\
\text { partidos políticos }\end{array}$ & $\begin{array}{c}\text { Confianza en las } \\
\text { Instituciones }\end{array}$ & $\begin{array}{c}\text { Interés por la } \\
\text { política }\end{array}$ & $\begin{array}{c}\text { Intención de } \\
\text { participar en la } \\
\text { política }\end{array}$ \\
\hline La inseguridad & 0,7 & 0,8 & 0,7 & 0,8 & 0,8 \\
\hline El desempleo & 0,7 & 0,8 & 0,7 & 0,8 & 0,8 \\
\hline La economía & 0,7 & 0,8 & 0,7 & 0,8 & 0,8 \\
\hline $\begin{array}{c}\text { El crimen organizado y } \\
\text { el narcotráfico }\end{array}$ & 0,7 & 0,8 & 0,7 & 0,8 & 0,8 \\
\hline $\begin{array}{c}\text { La pobreza } \\
\text { La Eficacia }\end{array}$ & 0,7 & 0,8 & 0,7 & 0,8 & 0,8 \\
\hline $\begin{array}{c}\text { Gubernamental } \\
\text { La corrupción }\end{array}$ & 0,7 & 0,8 & 0,7 & 0,8 & 0,8 \\
\hline $\begin{array}{c}\text { La vida interna en los } \\
\text { partidos políticos }\end{array}$ & 0,7 & 0,8 & 0,7 & 0,8 & 0,8 \\
\hline $\begin{array}{c}\text { Catástrofe o desgracia } \\
\text { natural }\end{array}$ & 0,7 & 0,8 & 0,7 & 0,8 & 0,8 \\
\hline $\begin{array}{c}\text { Las elecciones de } \\
\text { candidatos a puestos } \\
\text { públicos }\end{array}$ & 0,7 & 0,7 & 0,7 & 0,7 & 0,7 \\
\hline $\begin{array}{c}\text { Las reformas, leyes } \\
\text { decretos }\end{array}$ & 0,7 & 0,8 & 0,7 & & 0,8 \\
\hline \begin{tabular}{c} 
La educación \\
\hline
\end{tabular} & 0,7 & 0,8 & 0,7 & 0,8 & 0,8 \\
\hline
\end{tabular}

Fuente: Elaboración propia usando FuzzyLog

En la presentación de la metodología, se mencionó que Gil Lafuente y Barcellos (2010) indican que la matriz $\left[\mathrm{D}^{*}\right]$ capta las relaciones causales iniciales afectadas por la posible incidencia interpuesta de alguna causa o algún efecto. Por tanto, de acuerdo a la teoría de los efectos olvidados desarrollada por Kaufmann y Gil Aluja (1988), si obtenemos la matriz diferencia celda por celda, entre la matriz de incidencias de segundo orden $\left[D^{*}\right]$ y la matriz de incidencias directas $[D]$, obtendremos la matriz de efectos olvidados: $[O]=\left[D^{\star}\right]-[D]$ Matriz $N^{\circ} 5$.

\footnotetext{
${ }^{1}$ Los Derechos de uso corresponden a la Dra. Anna María Gil Lafuente, investigadora de la Universidad de Barcelona. http://www.fuzzyeconomics.com/fuzzylog

"Visión de Futuro" Año 18, Volumen No 25 No 1, Enero - Junio 2021 - Pág 1 - 23

URL de la Revista: http://visiondefuturo.fce.unam.edu.ar/index.php/visiondefuturo/index

URL del Documento: https://visiondefuturo.fce.unam.edu.ar/index.php/visiondefuturo/issue/view/19

ISSN 1668 - 8708 - Versión en Línea

E-mail: revistacientifica@fce.unam.edu.ar
} 
Matriz $\mathbf{N}^{\circ}$ 5. Matriz [0] de efectos olvidados

\begin{tabular}{|c|c|c|c|c|c|}
\hline $\begin{array}{c}{[\mathrm{O}]=\left[\mathrm{D}^{*}-\mathrm{D}\right]} \\
\text { causas } \rightarrow \text { efectos }\end{array}$ & $\begin{array}{c}\text { Confianza en los } \\
\text { gobernantes en } \\
\text { general }\end{array}$ & $\begin{array}{l}\text { Confianza en los } \\
\text { partidos políticos }\end{array}$ & $\begin{array}{l}\text { Confianza en las } \\
\text { Instituciones }\end{array}$ & $\begin{array}{c}\text { Interés por la } \\
\text { política }\end{array}$ & $\begin{array}{l}\text { Intención de } \\
\text { participar en la } \\
\text { política }\end{array}$ \\
\hline La inseguridad & 0 & 0,3 & 0,2 & 0,1 & 0,3 \\
\hline El desempleo & 0 & 0,3 & 0,2 & 0,1 & 0,3 \\
\hline La economía & 0 & 0,3 & 0,2 & 0,1 & 0 \\
\hline $\begin{array}{c}\text { El crimen organizado y } \\
\text { el narcotráfico }\end{array}$ & 0 & 0,1 & 0,2 & 0,1 & 0,3 \\
\hline La pobreza & 0 & 0,3 & 0,2 & 0,1 & 0,1 \\
\hline $\begin{array}{c}\text { La Eficacia } \\
\text { Gubernamental }\end{array}$ & 0 & 0,1 & 0 & 0,1 & 0,1 \\
\hline La corrupción & 0 & 0 & 0 & 0 & 0,1 \\
\hline $\begin{array}{l}\text { La vida interna en los } \\
\text { partidos políticos }\end{array}$ & 0,2 & 0,1 & 0 & 0,1 & 0,3 \\
\hline $\begin{array}{c}\text { Catástrofe o desgracia } \\
\text { natural }\end{array}$ & 0,4 & 0,4 & 0,4 & 0,2 & 0,2 \\
\hline $\begin{array}{l}\text { Las elecciones de } \\
\text { candidatos a puestos } \\
\text { públicos }\end{array}$ & 0 & 0,1 & 0 & 0,1 & 0,1 \\
\hline $\begin{array}{c}\text { Las reformas, leyes o } \\
\text { decretos }\end{array}$ & 0 & 0 & 0 & 0,1 & 0,1 \\
\hline La educación & 0 & 0,1 & 0 & 0,1 & 0 \\
\hline
\end{tabular}

Fuente: Elaboración propia usando FuzzyLog

\section{Resultados}

Una primera reflexión general sobre la matriz de efectos olvidados (Matriz $\mathrm{N}^{\circ} 5$ ), es que los valores de las celdas muy cercanos a cero o incluso cero, se interpretan como niveles en donde no hay efectos olvidados entre los temas de la agenda pública y las actitudes políticas de los ciudadanos. Por el contrario, si el valor numérico se aleja de cero, eso indica un efecto olvidado entre alguna causa o algún efecto. En el caso que nos ocupa, hemos determinado que valores iguales o superiores a 0.3 son las relaciones de incidencias ocultas. Es decir, las 11 celdas en gris muestran los efectos olvidados de una causa sobre un efecto.

Con la finalidad de evidenciar el funcionamiento de esta herramienta, sólo se presentan 2 efectos olvidados de los 11 identificados, que consideramos son representativos de la situación que tiene actualmente México. El primero de ellos, se muestra en la Tabla $N^{\circ} 4$ con su Figura $N^{\circ} 4$.

\footnotetext{
"Visión de Futuro" Año 18, Volumen No 25 N 1, Enero - Junio 2021 - Pág 1 - 23

URL de la Revista: http://visiondefuturo.fce.unam.edu.ar/index.php/visiondefuturo/index

URL del Documento: https://visiondefuturo.fce.unam.edu.ar/index.php/visiondefuturo/issue/view/19

ISSN 1668 - 8708 - Versión en Línea

E-mail: $\underline{\text { revistacientifica@fce.unam.edu.ar }}$
} 
Tabla $N^{\circ}$ 4. Primer efecto olvidado: La pobreza $\rightarrow$ Confianza en los partidos políticos

\begin{tabular}{|c|c|}
\hline Valor estimado inicialmente $[\mathrm{D}]$ & 0.5 \\
\hline Valor acumulado causa-efecto $\left[\mathrm{D}^{*}\right]$ & 0.8 \\
\hline Diferencia de valores (efecto olvidado) & 0.3 \\
\hline Relación clave interpuesta relevante: & La corrupción \\
\hline
\end{tabular}

Fuente: Elaboración propia con información obtenida de FuzzyLogic

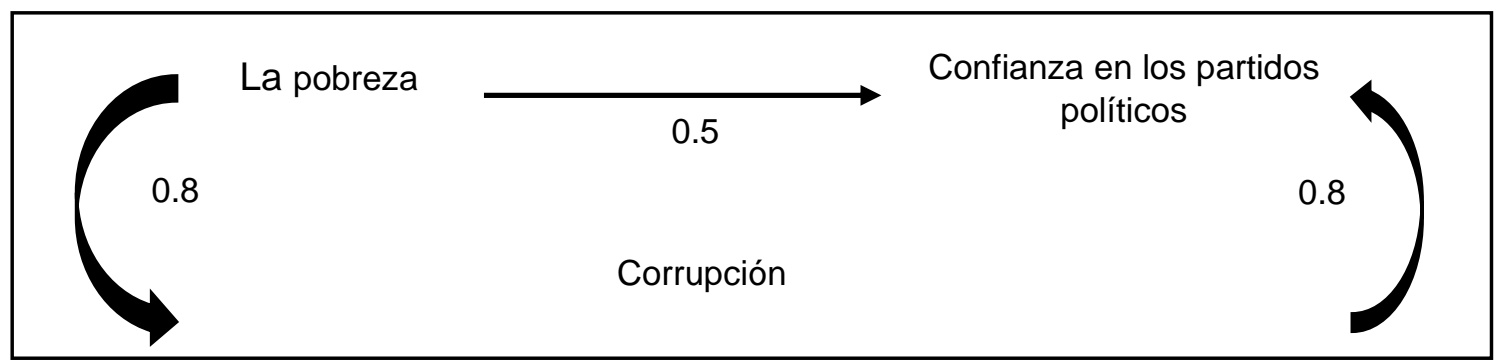

Figura $\mathbf{N}^{\circ}$ 4. Ilustración del primer efecto olvidado

Fuente: Elaboración propia con información de FuzzyLogic

Aunque inicialmente en la matriz [D], valuaron con 0.5 la incidencia entre La pobreza y la Confianza en los partidos políticos, al realizar la matriz de segundo orden [ $\left.\mathrm{D}^{\star}\right]$, la incidencia acumulada entre dichos elementos aumenta hasta 0.8 ya que hay un elemento interpuesto (Corrupción), que pertenece a los asuntos de la agenda pública y que puede potenciar y acumular efectos en la relación inicial no tomada en cuenta por los entrevistados, a causa del olvido en esa compleja relación de incidencias entre los temas de la agenda pública y las actitudes políticas del ciudadano.

Cabe aclarar que el valor de 0.8 mencionado antes, se determina tomando los valores de incidencia, a través del camino de las flechas anchas, para seleccionar el mínimo $(\wedge)$ entre ellos: $(0.8 \wedge 0.8=0.8)$. Esto muestra una oportunidad para los políticos ya que si desean aumentar la confianza en los partidos políticos, deben combatir la corrupción sin lugar a duda ya que tiene una fuerte incidencia en la confianza en los partidos.

De hecho el actual presidente de México, Andrés Manuel López Obrador, uno de sus principales argumentos que le sirvió para tener una contundente victoria en las elecciones del mes de julio del 2018 fue argumentar que en su gobierno, por primera vez en la historia del país eliminaría la corrupción.

El segundo efecto olvidado, se muestra en la Tabla $N^{\circ} 5$ con su Figura $N^{\circ} 5$.

\footnotetext{
"Visión de Futuro" Año 18, Volumen No 25 No 1, Enero - Junio 2021 - Pág 1 - 23

URL de la Revista: http://visiondefuturo.fce.unam.edu.ar/index.php/visiondefuturo/index

URL del Documento: https://visiondefuturo.fce.unam.edu.ar/index.php/visiondefuturo/issue/view/19

ISSN 1668 - 8708 - Versión en Línea

E-mail: revistacientifica@fce.unam.edu.ar
} 
Tabla $N^{\circ}$ 5. Segundo efecto olvidado: Catástrofe o desgracia natural $\rightarrow$ Confianza en los partidos políticos

\begin{tabular}{|c|c|}
\hline Valor estimado inicialmente [D] & 0.3 \\
\hline Valor acumulado causa-efecto [D*] & 0.7 \\
\hline Diferencia de valores (efecto olvidado) & 0.4 \\
\hline Relación clave interpuesta relevante: & $\begin{array}{c}\text { La economía y Confianza en los } \\
\text { gobernantes en general }\end{array}$ \\
\hline
\end{tabular}

Fuente: Elaboración propia con información obtenida de FuzzyLogic

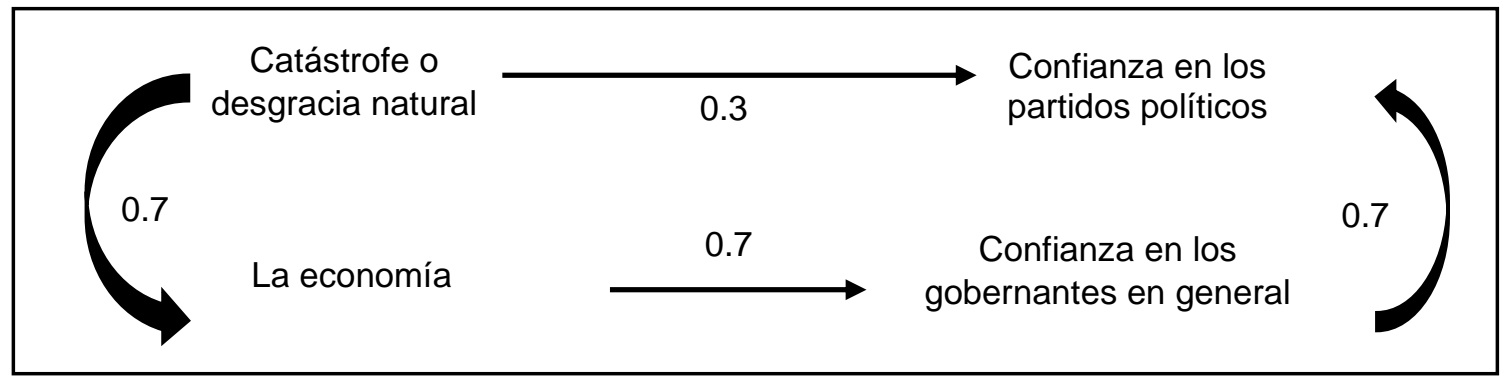

Figura $\mathbf{N}^{\circ} 5$. Ilustración del segundo efecto olvidado

Fuente: Elaboración propia con información de FuzzyLogic

En este caso, la relación de incidencia en la matriz [D], es de 0.3 entre Catástrofe o desgracia natural y Confianza en los partidos políticos. Al realizar la matriz de segundo orden $\left[D^{*}\right]$, la incidencia acumulada entre dichos elementos aumenta a 0.7 , como ya se ha mencionado, se toman los valores del camino con flechas anchas para seleccionar el mínimo $(\wedge)$ entre ellos: $(0.7 \wedge 0.7 \wedge 0.7=0.7)$. Por tanto, en este caso hay dos elementos interpuestos (La economía y la Confianza en los gobernantes en general) que pueden potenciar y acumular una mayor incidencia en la relación inicial no tomada en cuenta por los entrevistados, a causa del olvido en esa compleja relación de incidencias entre los asuntos de la agenda pública y las actitudes políticas de la gente.

Lo anterior muestra que al presentarse una catástrofe o desgracia natural, este evento incide en la economía y en la confianza en los gobernantes en general, siendo una oportunidad para fortalecer la confianza en los partidos políticos.

\section{CONCLUSIÓN}

En la actualidad, la situación política en México no está atravesando por su mejor momento: el desprestigio de los políticos, los partidos políticos y en general las instituciones de gobierno no son un tema menor. Inspirado en ello, el presente trabajo, pretende identificar elementos de oportunidad para mejorar la posición de la imagen política del país.

Hay una línea de investigación en temas políticos, que aborda el impacto o los efectos en las actitudes políticas del ciudadano a partir de los medios de comunicación e información

\footnotetext{
“Visión de Futuro" Año 18, Volumen No 25 N 1, Enero - Junio 2021 - Pág 1 - 23

URL de la Revista: http://visiondefuturo.fce.unam.edu.ar/index.php/visiondefuturo/index

URL del Documento: https://visiondefuturo.fce.unam.edu.ar/index.php/visiondefuturo/issue/view/19

ISSN 1668 - 8708 - Versión en Línea

E-mail: revistacientifica@fce.unam.edu.ar
} 
(agenda de medios en general). El presente estudio, puede formar parte de esa familia, siendo consciente de las diferencias que hay en las agendas utilizadas así como en las metodologías aplicadas.

La contribución del presente trabajo al marketing político, ha sido aportar un modelo de causalidad a través del significado de incidencia que tiene naturaleza subjetiva. El estudio se llevó a cabo en época de campaña presidencial en el año 2018, donde la gente tiene mayor consciencia política, a pesar de ello, se pudieron identificar elementos ocultos que al ser evidenciados permitirían a los actores políticos trabajar áreas de oportunidad con la finalidad de mejorar su vínculo afectivo, cognitivo y conductual o participativo con el ciudadano.

Las herramientas utilizadas ponen de manifiesto, la utilidad del expertizaje para obtener la opinión agregada de un conjunto de ciudadanos en relación con el tema del presente trabajo. Por otro lado, la Teoría de Efectos Olvidados se presenta como instrumento analítico y novedoso en el marketing político, que permite recuperar vínculos ocultos entre entidades que actúan como causas y entidades que actúan como efectos, ayudando con esto a mejorar la efectividad en la actuación de un político con su oferta a su audiencia objetivo.

Por último, consideramos que este estudio sirve de base a futuras investigaciones en el campo de las matrices de incidencia y la aplicación de la metodología de recuperación de efectos olvidados en otras áreas del marketing político.

\section{REFERENCIAS}

Álvarez, V. G. (2016). Modelo de efectos olvidados y exposición al riesgo cambiario en pymes manufactureras. Revista Científica Teorías, Enfoques y Aplicaciones en las Ciencias Sociales, 8(18), 67-84. Disponible en: https://dialnet.unirioja.es/servlet/articulo?codigo $=6577501$

Aruguete, N. (2009). Estableciendo la agenda. Los orígenes y la evolución de la teoría de la Agenda Setting. Ecos de la comunicación, 2(2), 11-38. Disponible en: https://repositorio.uca.edu.ar/handle/123456789/7119

Aruguete, N., \& Muñiz, C. (2012). Hábitos comunicativos y política. Efectos en las actitudes políticas de la población mexicana. Anagramas-Rumbos y sentidos de la comunicación, 10(20), 129-146. Disponible en: https://ssrn.com/abstract=2371855

Bouza, F. (2012). Las metodologías de agenda en el estudio de la opinión pública como base de la comunicación política. Revista Digital de Marketing Aplicado, 1(8), 41-54. Disponible en: http://redmarka.net/ra/doc.php?n=1654

Carreón, F. A., Figueroa, E. G., \& Montoya, D. A. (2017). Los Efectos Olvidados como una Herramienta en la Identificación de las Estrategias más Influyentes para la Consecución

\footnotetext{
"Visión de Futuro" Año 18, Volumen N$^{0} 25$ N 1, Enero - Junio 2021 - Pág 1 - 23

URL de la Revista: http://visiondefuturo.fce.unam.edu.ar/index.php/visiondefuturo/index

URL del Documento: https://visiondefuturo.fce.unam.edu.ar/index.php/visiondefuturo/issue/view/19

ISSN 1668 - 8708 - Versión en Línea

E-mail: revistacientifica@fce.unam.edu.ar
} 
de los Objetivos de una Organización. Revista de Gestión Empresarial y Sustentabilidad, $3(1), 1-21$.

Corral, D.L. (2016). Las agendas pública y mediática en México. Estudio preelectoral 20112012. Revista mexicana de opinión pública, (21), 13-30. Doi: https://doi.org/10.1016/j.rmop.2016.03.001

Duarte, M. A., \& Jaramillo, C. M. C. (2009). Cultura política, participación ciudadana y consolidación democrática en México. Espiral, 16(46), 137-171. Disponible en: www.scielo.org.mx/pdf/espiral/v16n46/v16n46a5.pdf

Encuesta de Cultura Política y Prácticas Ciudadanas (ENCUP), Secretaría de Gobernación. Disponible en: http://www.encup.gob.mx/

García, B. M.S. (2011). Las reformas electorales a nivel federal en México. El Cotidiano, (166), 79-91. Disponible en: http://www.redalyc.org/articulo.oa?id=32518423009

García, L. Ó. (2005). Desafectos y medios de comunicación: el estado de la cuestión de una relación difusa. Reflexión Política, 7 (14), 8-24. Disponible en: http://www.redalyc.org/articulo.oa?id=11001402

García, M.J. (2011). Encuadres, conflictos y efectos de agenda. Zer,16(31), 167-181. Disponible en: http://www.ehu.eus/ojs/index.php/Zer/article/view/4835/4705

García Montaño, J. (2004). El malestar de la democracia en México: elecciones, cultura política, instituciones y nuevo autoritarismo (1a. ed.). Madrid, España: Plaza y Valdés Editores.

Gil Aluja, J. (2002). Introducción de la Teoría de la incertidumbre en la gestión de empresas. Vigo, España: Editorial Milladoiro.

Gil Lafuente, A.M. \& Barcellos, L. (2010). Una aplicación de la metodología de los efectos olvidados: los factores que contribuyen al crecimiento sostenible de la empresa. Cuadernos del CIMBAGE, (12), 23-52. Disponible en: http://ojs.econ.uba.ar/ojs/index.php/CIMBAGE/issue/view/62/showToc

Kaufmann, A., \& Gil Aluja, J. (1988). Modelos para la investigación de efectos olvidados. Barcelona, España: Milladoiro.

Kaufmann, A., \& Gil Aluja, J. (1993). Técnicas especiales para la gestión de expertos. Vigo, España: Milladoiro.

Macassi, L., S. (1999). Nuevos escenarios para las “Agendas Públicas”. Estudios sobre las culturas contemporáneas, 5(9), 113-139. Disponible en: http://www.redalyc.org/articulo.oa?id=31600906

Maldonado, C., \& Casar, M. (2008). Formación de agenda y procesos de toma de decisiones: una aproximación desde la ciencia política. Documentos de trabajo cide 2008. (207). Disponible en: http://cide.repositorioinstitucional.mx/jspui/handle/1011/227

\footnotetext{
"Visión de Futuro" Año 18, Volumen N$^{0} 25$ N 1, Enero - Junio 2021 - Pág 1 - 23

URL de la Revista: http://visiondefuturo.fce.unam.edu.ar/index.php/visiondefuturo/index

URL del Documento: https://visiondefuturo.fce.unam.edu.ar/index.php/visiondefuturo/issue/view/19 
Mateos Díaz, A. (2004). Una aproximación a las actitudes políticas de los españoles mediante una estructura dimensional inductiva. Estudios Socio-Jurídicos, 6(2), 90-116. Disponible en: https://dialnet.unirioja.es/servlet/articulo?codigo=2314925

McCombs, M., \& Evatt, D. (1995). Los temas y los aspectos: explorando una nueva dimensión de la agenda setting. Comunicación y sociedad, 8(1), 7-32. Disponible en: https://dialnet.unirioja.es/servlet/articulo?codigo $=4323749$

Morris, S. D. (2011). Mexico's political culture: The unrule of law and corruption as a form of resistance. Mexican Law Review, 3(2), 327-342. Disponible en: https://www.researchgate.net/publication/277204724

Norris, P. (2001). ¿Un círculo virtuoso? El impacto de las comunicaciones políticas en las democracias post-industriales. Revista Española de Ciencia Política, (4), 7-33. Traducción de Luis Ramiro Disponible en: https://recyt.fecyt.es/index.php/recp/article/view/37313/20831

Peschard, J. (2019). La cultura política democrática (Segunda edición). Ciudad de México: Instituto Nacional Electoral.

Petrone, F. (2009). Estudio de agenda setting: Conceptos, metodología y bordajes posibles. V Jornadas de Jóvenes Investigadores. Instituto de Investigaciones Gino Germani, Facultad de Ciencias Sociales, Universidad de Buenos Aires, Buenos Aires. Disponible en: https://www.aacademica.org/000-089/234

Robinson, M. (1976). Public Affairs Television and the Growth of Political Malaise: The Case of "The Selling of the Pentagon". The American Political Science Review, 70(2), 409432. DOI: https://doi.org/10.2307/1959647

Rodríguez, J.M., Ramírez, M.A. \& Díaz, V. (2008). Efectos olvidados en las relaciones de causalidad de las acciones del sistema de capacitación en las organizaciones empresariales. Revista de métodos cuantitativos para la economía y la empresa, 5, 2948.Disponible: https://www.upo.es/revistas/index.php/RevMetCuant/article/view/2106 Rodríguez-Virgili, J., López-Escobar, E. \& Tolsá A. (2011). La percepción pública de los políticos, los partidos y la política, y uso de medios de comunicación. Comunicación y
Sociedad,24
7-39.
Disponible:

https://dialnet.unirioja.es/servlet/articulo?codigo=3817066

Rubio, J.M. (2009). Opinión Pública y medios de comunicación. Teoría de la agenda setting. Gazeta de Antropología, 25(1) 1-17. Disponible en: http://hdl.handle.net/10481/6843

Salazar-Garza, R. (2012). El peso mexicano: la gestión de cobertura del riesgo cambiario mediante la Teoría de los Efectos Olvidados (The Mexican Peso: Exchange Risk Coverage Management through the Forgotten Effects Theory). Journal of Economics,

\footnotetext{
"Visión de Futuro" Año 18, Volumen No 25 No 1, Enero - Junio 2021 - Pág 1 - 23

URL de la Revista: http://visiondefuturo.fce.unam.edu.ar/index.php/visiondefuturo/index

URL del Documento: https://visiondefuturo.fce.unam.edu.ar/index.php/visiondefuturo/issue/view/19

ISSN 1668 - 8708 - Versión en Línea

E-mail: revistacientifica@fce.unam.edu.ar
} 
Finance \& Administrative Science, 17(32). Disponible en: https://ssrn.com/abstract=2070231

Sarasola, M. (2004). Efectos olvidados en el diseño de una campaña proselitista. Revista Científica Visión de Futuro, 1(1), 12-28. Disponible en: https://dialnet.unirioja.es/servlet/articulo?codigo=7398097

Stubager, R. (2015). Inequality in the 'Conflict of Conflicts'? The Impact of Citizen Sophistication on Agenda-setting Effects. Political Studies, 63(4), 793-813. https://doi.org/10.1111/1467-9248.12131

Tamayo, M., \& Carrillo, E. (2005). La Formación de la Agenda Pública. Foro Internacional, 45(4), 658-681. Disponible en: http://www.redalyc.org/articulo.oa?id=59911177004

Tinto, A. J., Luna, A.K.A. \& Cisneros, Q. D. P. (2017). Teoría de los efectos olvidados en el rescate de la imagen comercial de los artesanos del calzado en el cantón Gualaceo provincia del Azuay, Ecuador. Visión Gerencial, (1), 24-42. Disponible en: https://www.redalyc.org/articulo.oa?id=465549683003

Tronco, José del. (2012). Las causas de la desconfianza política en México. Perfiles latinoamericanos, 20(40), 227-251. Disponible en: www.scielo.org.mx/scielo.php?script=sci_arttext\&pid=S0188-76532012000200009

\section{RESUMEN BIOGRÁFICO}

\section{Mauricio Ortigosa Hernández}

Doctor por la Universidad de Barcelona en Empresariales. Maestría en Administración de Empresas en el ITESM en México y Actuario por la UNAM. Actualmente, profesor-investigador en el Centro de Alta Dirección en Economía y Negocios de la Universidad Anáhuac México. Líneas de investigación: Modelos para el tratamiento de la incertidumbre.

\footnotetext{
"Visión de Futuro" Año 18, Volumen No 25 No 1, Enero - Junio 2021 - Pág 1 - 23 